\title{
Avaliação da Folha e do Colmo de Topo e Base de Perfilhos de Três Gramíneas Forrageiras. 1. Digestibilidade in vitro e Composição Química ${ }^{1}$
}

\author{
Domingos Sávio Queiroz², José Alberto Gomide ${ }^{3}$, José Maria ${ }^{3}$
}

\begin{abstract}
RESUMO - Foi avaliado o grau de correlação linear simples entre a digestibilidade in vitro da matéria seca (DIVMS) e a composição química de lâminas e bainhas foliares e, do colmo, amostrados no topo e na base de perfilhos de capim-elefante (Pennisetum purpureum, cv. Mott), capim-setária (Setaria anceps, cv. Kazungula) e capim-jaraguá (Hyparrhenia rufa, Nees Stapf). Os valores de DIVMS e os teores de proteína bruta (PB) e parede celular (FDN) exibiram gradiente ao longo do perfil do perfilho e diferença entre as frações do perfilho. As folhas situadas no topo do perfilho mostraram maior conteúdo de PB e digestibilidade, apesar dos mais altos teores de FDN, que as folhas situadas na base dos perfilhos. As lâminas foliares mostraram valores relativamente mais altos de DIVMS, PB e FDN que a bainha foliar. Nenhuma correlação foi observada entre os componentes químicos e a DIVMS da lâmina foliar do topo do perfilho. Apenas o teor de lignina apresentou correlação significativa $(r=-0,53)$ com a DIVMS, quando dados das lâminas foliares de topo e base do perfilho foram agrupados. Os teores de fibra em detergente neutro, fibra em detergente ácido, proteína bruta e lignina propiciaram correlações com a DIVMS da lâmina foliar de base, da bainha foliar e do colmo.
\end{abstract}

Palavras-chave: composição química, correlação linear, digestibilidade in vitro, Hyparrhenia rufa, Pennisetum purpureum, Setaria anceps

\section{Evaluation of Top and Bottom Leaf and Stem Fractions from Tiller of Three Forages Grasses. 1. In vitro Disappearance and Chemical Composition}

\begin{abstract}
The degree of a simple linear correlation among the in vitro dry matter disappearance (IVDMD) and chemical composition of the leaf blades and sheath, and stems, sampled from the top and bottom tillers of dwarf elefantgrass (Pennisetum purpureum, Schumach cv. Mott, setariagrass (Setaria anceps, Stapf ex Massey cv. Kazungula) and jaraguagrass (Hyparrhenia rufa, Nees Stapf), was evaluated. A gradient pattern was observed for IVDMD, crude protein (CP) and cell wall (NDF) along the tiller profiles and difference among the tiller fractions. The leaves inserted on the top of tiller showed higher CP content and digestibility, despite of the higher NDF content than those leaves inserted on the bottom level of the tiller. The leaf blades showed a relative high IVDMD, CP and NDF than leaf sheath. No correlation was observed among the chemical components and IVDMD of the top leaf blades of the tiller. Only the lignin content showed a significant correlation $(r=-0.53)$ with the IVDMD, when the top and bottom leaf blades were grouped. The neutral detergent fiber, acid detergent fiber, crude protein and lignin showed correlation with the IVDMD of bottom leaf blades, leaf sheath and stem.
\end{abstract}

Key Words: chemical composition, linear correlation, in vitro disappearance, Hyparrhenia rufa, Pennisetum purpureum, Setaria anceps

\section{Introdução}

A estimativa do valor nutritivo das forrageiras é de grande importância prática, seja para permitir adequado balanceamento de dietas à base de volumosos ou para fornecer subsídios para melhorar o valor nutritivo de forrageiras, por meio de seleção genética, técnicas de manejo mais adequadas ou, ainda, do tratamento de resíduos forrageiros.

A análise química e a digestibilidade são os métodos tradicionalmente usados para estimar o valor nutritivo. A digestibilidade in vitro é uma técnica que guarda alta correlação com a digestibilidade in vivo (TILLEY e TERRY, 1963), notadamente em forrageiras (McLEOD e MINSON, 1969). A técnica da digestibilidade in vitro tem se revelado uma ferramenta extremamente útil para os nutricionistas de ruminantes, melhoristas e estudiosos de forrageiras, pela possibilidade de avaliar amostras pequenas e biologicamente bem definidas (WILSON, 1985). Essa técnica facilita a investigação das causas da baixa digestibilidade, além de possibilitar o estudo das influências de fatores morfológicos, anatômicos, ontogênicos e de ambiente sobre a digestibilidade.

A análise química, por outro lado, apresenta limitações, pois nem sempre há boa relação entre a digestibilidade da forragem e sua composição química. Vários fatores estão envolvidos. Na análise de

\footnotetext{
1 Parte da Tese de Doutorado em Zootecnia do primeiro autor apresentada à UFV.

2 Pesquisador da EPAMIG/CTZM, Casa 46, Vila Gianetti, Viçosa-MG. E-mail: dqueiroz@mail.ufv.br

3 Professor da UFV-Viçosa, MG. E-mail: jagomide@mail.ufv.br
} 
forrageiras, depara-se com amostras que estão sujeitas aos efeitos dos mais variados fatores, como espécie, origem, condições de cultivo, condições e ambiente durante o crescimento, maturidade, proporção colmo/folha, nível de inserção da fração amostrada, proporção de tecidos nas frações botânicas, características estruturais da parede celular, entre outros. A interferência de todas estas variáveis dificulta o entendimento não só da significância da composição química, mas também do modo como se relaciona com a digestibilidade. Prova disso são os estudos de digestão in vitro de materiais forrageiros apresentados por RALPH e HELM (1993), que mostram semelhança de composição química entre o resíduo indigestível e o material original. VAN SOEST(1994) afirma que a extração da parede celular das forrageiras e seu fracionamento químico, para obter frações de carboidratos que sejam relevantes à qualidade nutricional para ruminantes, é um problema ainda não resolvido.

O grande mérito do método in vitro deve-se à sensibilidade dos microorganismos e enzimas a fatores não-detectados quimicamente que influenciam a taxa e a extensão de digestão. Nesse aspecto, o método supera a limitação da análise química, que é a incapacidade de detectar tais interações entre os componentes da parede celular das plantas. Por isso, segundo VAN SOEST (1982), os sistemas químicos de análise, conquanto mais rápidos e de mais alta precisão, não refletem bem a realidade biológica, o que pode ser alcançado com o sistema in vitro.

O objetivo deste trabalho foi avaliar a composição química e a digestibilidade in vitro da matéria seca de lâminas e bainhas foliares e do colmo, amostrados no topo e na base de perfilhos de três gramíneas forrageiras, em duas estações de crescimento, bem como o grau de correlação linear entre as duas variáveis.

\section{Material e Métodos}

Foram estudadas as gramíneas forrageiras capim-jaraguá (Hyparrhenia rufa, Nees Stapf), capim-setária (Setaria anceps, Stapf ex Massey cv. kazungula) e capim-elefante (Pennisetum purpureum, Schumach var. Mott). O experimento foi conduzido em área do Departamento de Zootecnia do Centro de Ciências Agrárias da Universidade Federal de Viçosa, Minas Gerais. Viçosa localiza-se a $20^{\circ} 45^{\prime}$ de latitude sul e $42^{\circ} 54^{\prime}$ 'de longitude oeste, a uma altitude média de $650 \mathrm{~m}$. Seu clima é do tipo Cwb (classificação de Köppen), clima tropical de altitude, com verões quentes e chuvosos.

O solo da área experimental, com declividade de $20 \%$, foi classificado como Podzólico Vermelhoamarelo distrófico, textura franco-argilo-arenosa, com a seguinte composição química: $\mathrm{pH}$ (água), 5,8; fósforo, $2,3 \mathrm{ppm}$; potássio, $42 \mathrm{ppm}$; cálcio, $2,1 \mathrm{meq} /$ $100 \mathrm{~cm}^{3}$; magnésio, $0,78 \mathrm{meq} / 100 \mathrm{~cm}^{3}$ e alumínio, 0,0 $\mathrm{meq} / 100 \mathrm{~cm}^{3}$. Antes da instalação do experimento, a área apresentou cobertura uniforme de capim-gordura (Melinis minutiflora, Beauv).

O plantio foi realizado em parcelas de $20 \mathrm{~m}^{2}$, em dezembro/92, sendo as gramíneas capim-jaraguá e capim-setária estabelecidas por sementes, em sulcos espaçados de $25 \mathrm{~cm}$ e o capim-elefante, por mudas, em fileiras espaçadas de $50 \mathrm{~cm}$. Uma adubação na base de $100 \mathrm{~kg} /$ ha de $\mathrm{P}_{2} \mathrm{O}_{5}$, na forma de superfosfato simples, foi feita no sulco de plantio.

Em novembro/93, a área experimental foi submetida a corte de uniformização, seguido por uma adubação com $100 \mathrm{~kg} / \mathrm{ha}$ de $\mathrm{P}_{2} \mathrm{O}_{5}$, na forma de superfosfato triplo. Em 15/12/93, novo corte geral de condicionamento para início das avaliações foi feito, seguido de uma adubação com $300 \mathrm{~kg} / \mathrm{h}$ a de sulfato de amônia e $100 \mathrm{~kg} / \mathrm{ha}$ de cloreto de potássio. Esse corte foi praticado rente ao solo no capim-elefante e a $3 \mathrm{~cm}$ do solo nas demais gramíneas. Durante a fase de crescimento, foram feitas irrigações sempre que necessário. O momento da amostragem de cada espécie foi determinado pelo aparecimento dos primeiros sinais de senescência (secamento do ápice da lâmina) das folhas inferiores. Assim, foram praticadas colheitas em 24 e 25/01/94, no capim-jaraguá; 26 e 27/01/94, no capim-setária; e 31/01 e 01/02/94, no capim-elefante. Este crescimento correspondeu ao período de verão. As médias das temperaturas máxima e mínima durante o primeiro período de crescimento foram 27,6 e $18,6^{\circ} \mathrm{C}$, respectivamente.

Amostras de um segundo período de crescimento, em março/abril, correspondendo ao outono, foram avaliadas. O corte de condicionamento para este crescimento foi realizado em 09/03/94, seguido de uma adubação com $300 \mathrm{~kg} / \mathrm{ha}$ de sulfato de amônia e $100 \mathrm{~kg} / \mathrm{ha}$ de cloreto de potássio. Da mesma forma que no primeiro crescimento, as amostras foram obtidas quando do aparecimento dos primeiros sinais de senescência das folhas inferiores. Entretanto, a amostragem do capim-setária foi antecipada, devido à ocorrência de senescência precoce de folhas ainda novas. Detectou-se a presença de pontuações necrosadas, mesmo em folhas recém-emergidas, cuja 
Rev. bras. zootec.

causa não foi identificada. O corte do capim-setária foi feito em 12 e 13/04/94; do capim-jaraguá, em 26 e 27/04/94; e do capim-elefante, em 03 e 04/05/94. As médias das temperaturas máxima e mínima, durante o segundo período de crescimento, foram 26,5 e $17,2^{\circ} \mathrm{C}$, respectivamente.

Para a amostragem, em cada estação, touceiras foram colhidas ao acaso na parcela, evitando-se as bordaduras, sendo cortadas rente ao solo e imediatamente colocadas em um balde com uma camada de água de aproximadamente $15 \mathrm{~cm}$, para evitar murchamento dos perfílhos. Após a colheita, as amostras foram levadas ao laboratório para serem processadas.

De cada perfilho amostraram-se a lâmina, a bainha e o respectivo entrenó da última folha recémexpandida (topo do perfilho) e de uma folha adulta em início de senescência (base do perfilho). Uma vez separado, este material foi levado à estufa para secagem a $60^{\circ} \mathrm{C}$. Depois de secas, as amostras foram pesadas, moídas em moinho tipo Willey com peneira de $1 \mathrm{~mm}$ de abertura e acondicionadas em vidros para análises posteriores.

Foram analisados os teores de matéria seca a $105^{\circ} \mathrm{C}$, segundo SILVA (1990); proteína bruta, segundo o método semimicro Kjeldhal, usando o fator 6,25 para conversão de nitrogênio em proteína bruta (ASSOCIATION OF OFICIAL AGRICULTURAL CHEMIST-AOAC, 1970); e fibra em detergente neutro, fibra em detergente ácido e lignina no resíduo do detergente ácido com uso de permanganato de potássio, segundo Van Soest e Wine (1967), citados por SILVA (1990). A digestibilidade in vitro da matéria seca seguiu a metodologia de TILLEY e TERRY (1963), modificada por MARTEN e HALGERSON, s.d.

Os dados foram submetidos à análise de variância por meio do SAS. A tardia elevação do meristema apical em capim-jaraguá conduziu a amostragem somente de folhas na colheita de verão, apesar do corte rente ao solo, ensejando a realização de duas análises de variância (ANOVA 1 e ANOVA 2), segundo o modelo:

$$
\begin{aligned}
& \mathrm{Y}_{\mathrm{ijklm}}=\mu+\mathrm{E}_{\mathrm{i}}+\mathrm{P}_{\mathrm{j}}+\mathrm{I}_{\mathrm{k}}+\mathrm{C}_{1}+\mathrm{EP}_{\mathrm{ij}}+\mathrm{EI}_{\mathrm{ik}}+ \\
& \mathrm{EC}_{\mathrm{il}}+\mathrm{PI}_{\mathrm{jk}}+\mathrm{PC}_{\mathrm{jl}}+\mathrm{IC}_{\mathrm{kl}}+\mathrm{EPI}_{\mathrm{ijk}+} \mathrm{EPC}_{\mathrm{ijl} 1+} \mathrm{EIC}_{\mathrm{ikl}} \\
& +{ }_{+} \mathrm{PIC}_{\mathrm{jkl}+} \mathrm{EPIC}_{\mathrm{ijkl}+} \mathrm{e}_{\mathrm{ijklm}} \\
& \text { em que } \\
& \mathrm{Y}_{\mathrm{ijklm}}=\text { valor da ma } \mathrm{a} \text { observação, na } 1 \underline{\mathrm{a}} \text { estação, na } \\
& \mathrm{k}^{\underline{a}} \text { inserção, da } \mathrm{j}^{\mathrm{a}} \text { fração do perfilho, da } \mathrm{i}^{\mathrm{a}} \text { espécie; } \\
& \mu \quad=\text { média geral; } \\
& \mathrm{E}_{\mathrm{i}} \quad=\text { efeito da } \mathrm{i}^{\mathrm{a}} \text { espécie, sendo }
\end{aligned}
$$$$
\text { ANOVA 1, i = 1, 2, 3, espécies (jaraguá, setária }
$$
e elefante); e
ANOVA 2, i = 1, 2 espécies (setária e elefante).

$\mathrm{Pj} \quad=$ efeito da $\mathrm{j}$ a fração do perfilho, sendo

ANOVA 1, j = 1, 2 frações (lâmina e bainha) e

ANOVA 2, j=1, 2, 3, frações (lâmina, bainha e colmo).

$\mathrm{I}_{\mathrm{k}} \quad=$ efeito da $\mathrm{k}^{\mathrm{a}}$ inserção, sendo $\mathrm{k}=1,2$ (topo e base do perfilho);

$\mathrm{C}_{1} \quad=$ efeito da $1^{\mathrm{a}}$ estação, sendo $1=1,2$ (verão e outono);

$\mathrm{EP}_{\mathrm{ij}}$ = interação dos efeitos da $\mathrm{i} \underline{\mathrm{a}}$ espécie com a $\mathrm{j}^{\mathrm{a}}$ fração do perfilho;

$\mathrm{EI}_{\mathrm{ik}}=$ interação dos efeitos da i ${ }^{\mathrm{a}}$ espécie com a k- inserção;

$\mathrm{EC}_{\mathrm{il}}=$ interação dos efeitos da $\mathrm{i}^{\mathrm{a}}$ espécie com a 1 a estação;

$\mathrm{PI}_{\mathrm{jk}}=$ interação dos efeitos da $\mathrm{j}^{\mathrm{a}}$ fração do perfilho com a k inserção;

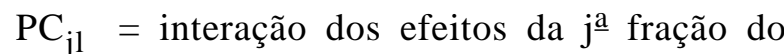
perfilho com a la estação;

$\mathrm{IC}_{\mathrm{kl}}=$ interação dos efeitos da $\mathrm{k}^{\underline{\mathrm{a}}}$ inserção com a $1^{1}$ estação;

$E P I_{i j k}=$ interação dos efeitos da $i^{a} \underline{a}$ espécie com a $\mathrm{j}^{\mathrm{a}}$ fração do perfilho com a $\mathrm{k}^{\mathrm{a}}$ inserção;

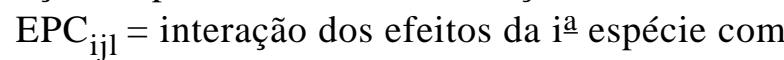
a j $j^{\mathrm{a}}$ fraçã̃o do perfilho com a $\mathrm{l}^{\mathrm{a}}$ estação;

$\mathrm{EIC}_{\mathrm{ikl}}=$ interação dos efeitos da $\mathrm{i}^{\mathrm{a}}$ espécie com a $\mathrm{k}^{\mathrm{a}}$ inserção com a $1^{\mathrm{a}}$ estação;

$\mathrm{PIC}_{\mathrm{jk}}=$ interação dos efeitos da $\mathrm{j}$ a fração do perfilho com a k $\mathrm{k}^{\mathrm{a}}$ inserção com a $\mathrm{l}^{\mathrm{a}}$ estação;

EPIC $_{i j k l}=$ interação dos efeitos da i $i^{a}$ espécie com a $\mathrm{j}^{\mathrm{a}}$ fração do perfilho com a $\mathrm{k}^{\underline{\mathrm{a}}}$ inserção com a ${ }^{\mathrm{a}}$ estação; e

$\mathrm{e}_{\mathrm{ijklm}}=$ erro aleatório associado a cada observação, $\mathrm{n}=1,2, \ldots 48$.

As interações significativas foram desdobradas e as médias, comparadas pelo teste Newman Keuls, a $5 \%$ de probabilidade, pelo SAEG. Coeficientes de correlação linear simples entre a DIVMS e as variáveis químicas foram calculados para todas as frações do perfilho, a lâmina foliar e cada fração do perfilho isoladamente.

\section{Resultados e Discussão}

Houve efeito $(\mathrm{P}<0,05)$ de espécie e estação, quando somente lâminas e bainhas foliares foram consideradas na análise. O capim-jaraguá, com $61,2 \%$ de coeficiente de digestibilidade in vitro da matéria seca (DIVMS), mostrou-se inferior $(\mathrm{P}<0,05)$ ao capim-elefante e ao capim-setária, que não diferiram entre si $(\mathrm{P}<0,05)$ e apresentaram digestibilidade de 
67,6 e 68,4\%, respectivamente. Amostras colhidas no verão apresentaram coeficientes de DIVMS superiores $(\mathrm{P}<0,05)$ aos daquelas colhidas no outono, sendo os valores médios de 67,4 e $64,0 \%$, respectivamente. Estes valores referem-se às médias para as frações lâminas e bainhas foliares.

Diferença de digestibilidade foi observada em função do nível de inserção da folha no perfilho, com valores mais baixos correspondendo às folhas da base, principalmente no caso da bainha foliar (Tabela 1). Lâminas e bainhas foliares inseridas no topo do perfilho eqüivaleram-se $(\mathrm{P}>0,05)$ em digestibilidade, ao passo que, na base do perfilho, a lâmina foliar se mostrou mais digestível.

A exclusão do capim-jaraguá e a inclusão do colmo na análise, além de elevar os coeficientes de DIVMS da lâmina e bainha foliares, fez desaparecer o efeito $(\mathrm{P}<0,05)$ do nível de inserção sobre a DIVMS das lâminas foliares do perfilho, sugerindo queda menos intensa na DIVMS da lâmina foliar de base do capim-elefante e capim-setária, em relação ao capim-jaraguá (Tabela 2). A diferença entre as lâminas de topo e base, que foi de 4,61 unidades percentuais considerando as três gramíneas (Tabela 1), diminuiu para 3,59 unidades percentuais, quando se excluiu o capim-jaraguá (Tabela 2). Diferença de digestibilidade foi observada em função do nível de inserção da bainha foliar no perfilho, com valores mais baixos correspondendo às bainhas de base. Maior variação na DIVMS entre frações do topo e base do perfilho foi observada para o colmo, para o qual se observou diferença de 24,5 unidades percentuais (Tabela 2). A mais alta DIVMS da porção do topo do colmo decorreu de seu estádio ainda meristemático, evidenciado durante a manipulação das amostras, contrastando com o crescente envelhecimento em direção à base do perfilho, que provocou intensa redução nos valores de digestibilidade in vitro, fato também observado por AKIN et al. (1977) em colmos de capimcoastal bermuda.

Apesar da intensa redução nos coeficientes de DIVMS da bainha foliar do topo para a base do perfilho, de 15,3 unidades percentuais (Tabela 1), este órgão apresentou pouca variação de seus componentes químicos (Tabela 3). WILSON (1976b) observou decréscimo de 12 a 19 unidades percentuais na digestibilidade em bainhas foliares de Panicum maximum var Trichoglume, cinco dias após a exteriorização da lígula da folha. Segundo esse autor, a lignificação das fibras esclerenquimáticas e o desenvolvimento de grossa cutícula, após a exposição da bainha foliar à atmosfera, explicam esse decréscimo.

A queda de 4,61 unidades percentuais na digestibilidade da lâmina foliar entre o topo e a base do perfilho foi bem menor que aquela observada para a bainha foliar e o colmo. No entanto, lâminas foliares de topo apresentaram 20 unidades percentuais a mais de FDN, em relação às lâminas da base do perfilho, na média das três espécies (Tabela 3 ). Dois aspectos devem ser considerados, o nível de inserção no perfilho e a idade das lâminas foliares no momento da amostragem. À mesma idade, WILSON (1976a) observou que lâminas foliares do topo do perfilho de Panicum maximum var. Trichoglume foram menos digestíveis, apresentando mais elevados teores de FDN que lâminas foliares da base. Com a maturidade, lâminas foliares de qualquer nível de inserção exibiram elevação de seus teores de FDN e redução da digestibilidade. No presente trabalho, a lâmina foliar amostrada no topo do perfilho era recémexpandida, o que pode explicar sua alta digestibilidade. A lâmina foliar amostrada na base do perfilho apresentava-se em início de senescência, com a digestibilidade reduzida pela maturidade. $\mathrm{O}$ mais alto nível de inserção explica os valores mais elevados do teor de FDN, conforme observado por WILSON (1976a), enquanto a menor maturidade justifica a mais alta digestibilidade da lâmina foliar do topo relativamente àquela da base do perfilho.

$\mathrm{Na}$ análise dos componentes químicos, o capimjaraguá apresentou teores mais elevados de FDN e FDA e mais baixos de proteína bruta (Tabela 3); observações que justificam a mais baixa digestibilidade de sua matéria seca. Mais altos teores de proteína bruta foram observados em folhas de capim-setária, seguidos pelo capim-elefante e capim-jaraguá; este último com valores mais baixos - tanto na lâmina quanto na bainha. Semelhantemente à DIVMS, mais altos teores de PB foram observados nas folhas de mais alto nível de inserção, bem como nas lâminas foliares relativamente às bainhas foliares.

Precoce desenvolvimento de colmo e hábito de florescimento não-determinado foram características que determinaram a amostragem de um colmo mais diferenciado no capim-setária em relação ao capimelefante. Como consequiência, o colmo de capimsetária apresentou teores mais elevados de FDN e FDA e mais baixos de proteína bruta (Tabela 3). A composição química das frações do perfilho foi fortemente influenciada pelo nível de inserção, à exceção da bainha foliar, cujas diferenças, embora significativas, são de menor magnitude. Assim, lâminas de folhas 
Rev. bras. zootec.

Tabela 1 - Digestibilidade in vitro da matéria seca ${ }^{1}$ (DIVMS) de frações do perfilho das três gramíneas, segundo os níveis de inserção

Table 1 - In vitro dry matter disappearance (IVDMD) of tiller fractions of three grasses, according to their insertion levels

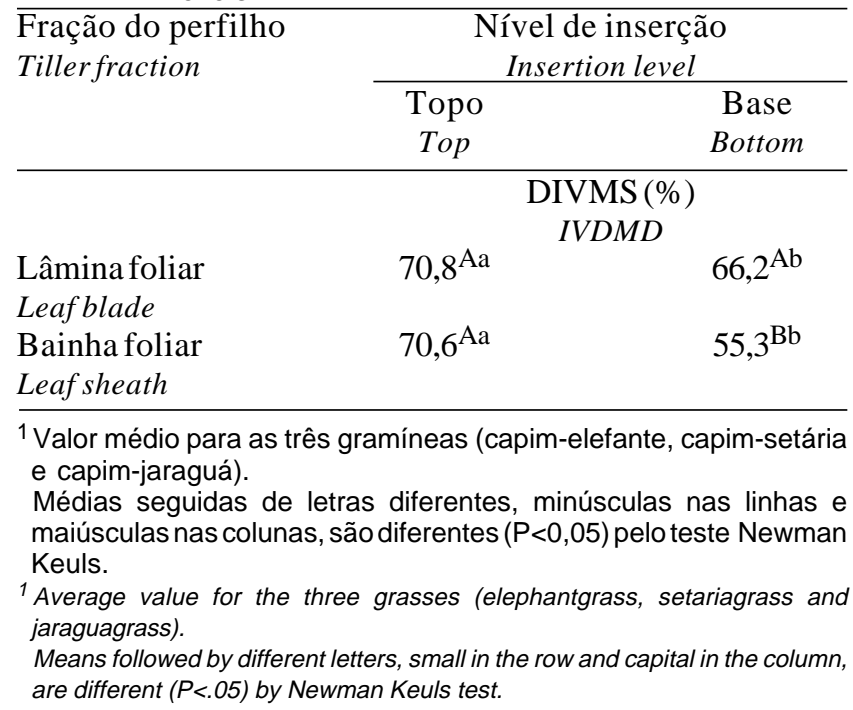

inseridas no topo do perfilho apresentaram teores de FDN e FDA mais elevados $(\mathrm{P}<0,05)$ que lâminas da base. Esta diferença foi mais expressiva no capimelefante, com 19,3 unidades percentuais, seguida pelo capim-setária, com 15,2 unidades percentuais, e capim-jaraguá, com 4,7 unidades percentuais.

Os teores de lignina foram mais baixos no capimsetária $(6,9 \%)$ do que no capim-elefante e capimjaraguá, os quais não diferiram entre si, apresentando teor médio de $8,5 \%$, média de todas as frações amostradas (Tabela 4). Apenas na fração colmo houve efeito $(\mathrm{P}<0,05)$ do nível de inserção sobre os teores de lignina, sendo observados valores mais altos na base do colmo. Lâminas e bainhas foliares não exibiram efeito do nível de inserção sobre seus teores de lignina.

Capim-elefante e capim-setária não diferiram $(\mathrm{P}>0,05)$ entre si quanto aos teores de FDN, lignina e DIVMS em lâminas e bainhas de sua folha de topo do perfilho; contudo, a lâmina foliar apresentou teores de proteína bruta bem mais elevados que a bainha foliar, enquanto a bainha foliar do capim-jaraguá apresentou teores mais elevados de FDN e FDA. Para frações do topo de capim-coastal bermuda, AKIN et al. (1977) observaram maior digestibilidade da bainha foliar em comparação à lâmina foliar, embora maiores teores de FDN e lignina e menores de proteína bruta correspondessem à bainha foliar.

Um aspecto a considerar é que, no momento da
Tabela 2 - Digestibilidade in vitro da matéria seca (DIVMS) de frações do perfilho de capim-setária e capimelefante, segundo os níveis de inserção

Table 2 - In vitro dry matter disappearance (IVDMD) of tiller fractions of setariagrass and elefantgrass, according to their insertion levels

\begin{tabular}{|c|c|c|}
\hline \multirow[t]{2}{*}{$\begin{array}{l}\text { Fração do perfilho } \\
\text { Tillerfraction }\end{array}$} & \multicolumn{2}{|c|}{$\begin{array}{l}\text { Nível de inserção } \\
\text { Insertion level }\end{array}$} \\
\hline & $\begin{array}{l}\text { Topo } \\
\text { Top }\end{array}$ & $\begin{array}{c}\text { Base } \\
\text { Bottom }\end{array}$ \\
\hline & \multicolumn{2}{|c|}{ DIVMS (\%) } \\
\hline & & \\
\hline $\begin{array}{l}\text { Lâmina foliar } \\
\text { Leaf blade }\end{array}$ & $72,1^{\mathrm{Ba}}$ & $68,5^{\mathrm{Aa}}$ \\
\hline Bainha foliar & $73,4^{\mathrm{Ba}}$ & $58,1^{\mathrm{Bb}}$ \\
\hline $\begin{array}{l}\text { Leaf sheath } \\
\text { Colmo }\end{array}$ & $86,3^{\mathrm{Aa}}$ & $61,8^{\mathrm{Bb}}$ \\
\hline
\end{tabular}

Médias seguidas de letras diferentes, minúsculas nas linhas e maiúsculas nas colunas, são diferentes $(P<0,05)$ pelo teste Newman Keuls.

Means followed by different letters, small in the row and capital in the column, are different $(P<.05)$ by Newman Keuls test.

amostragem, lâmina e bainha associadas apresentaram gradiente em idade. Sabe-se que o crescimento das folhas nas gramíneas se deve ao meristema intercalar existente na base da lâmina e bainha foliares. A lâmina foliar, que cresce mais rapidamente que a bainha, paralisa seu crescimento após a diferenciação da lígula, enquanto a bainha continua a crescer por mais algum tempo, após a completa expansão da lâmina foliar (GOMIDE, 1988; LANGER, 1972). Ao se amostrar a folha mais recentemente expandida, muitas vezes a bainha foliar ainda se encontra em crescimento, o que justificaria seu alto coeficiente de DIVMS, equivalente ao observado para a lâmina foliar.

O efeito da estação de crescimento sobre a composição química das gramíneas mostrou-se variável, dependendo da espécie. Em capim-elefante e capim-jaraguá, a variação entre as estações do ano decorreu da amostragem das gramíneas no estádio vegetativo no verão e início de florescimento no outono. A passagem do estádio vegetativo para reprodutivo determinou intensa redução no comprimento da lâmina foliar e na relação lâmina foliar/colmo + bainha foliar (dados não apresentados). Apesar disso, o capim-jaraguá não apresentou alterações significativas em sua composição química, atribuível às estações de crescimento. Por outro lado, o capimelefante apresentou elevação $(\mathrm{P}<0,05)$ dos teores de FDA, de 37,6 para $39,4 \%$, quando somente a fração 


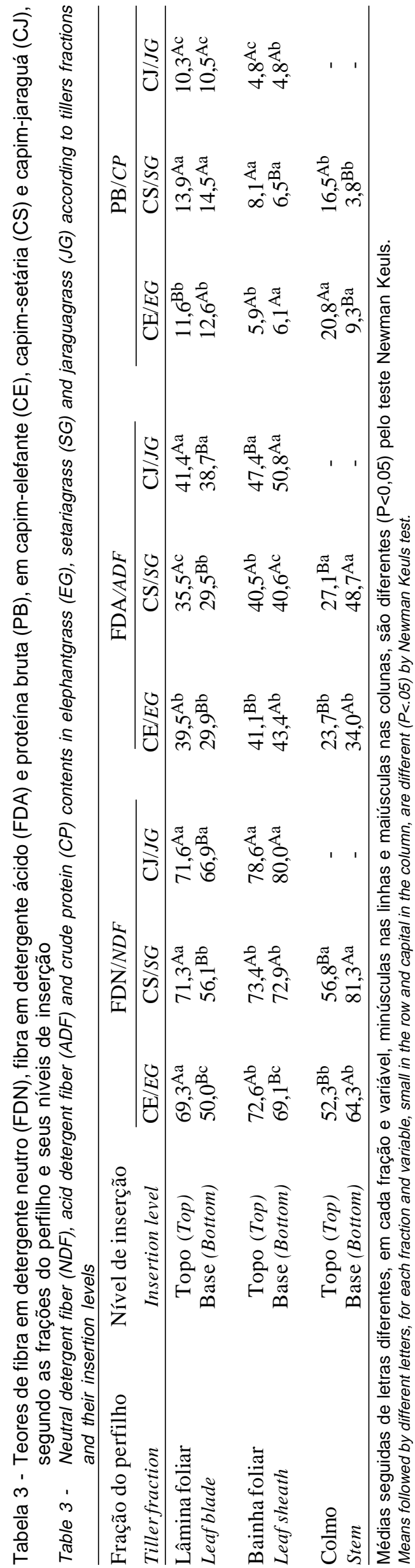

foliar foi considerada, e dos teores de FDN, de 60,2 para $65,7 \%$, e FDA, de 34,0 para $36,6 \%$, quando se incluiu o colmo na análise, entre o verão e outono, respectivamente, sem alterações significativas dos demais componentes.

Em capim-setária, que apresenta hábito de crescimento não-determinado, a amostragem de verão coincidiu com o início do florescimento, ao passo que no outono a antecipação da amostragem propiciou a colheita de perfilhos ainda vegetativos. Ao contrário do capim-elefante, em capim-setária, os teores de FDA se reduziram $(\mathrm{P}<0,05)$ do verão para o outono, de 37,2 para $35,9 \%$ na fração foliar, redução que se acentuou com a inclusão do colmo, de 38,1 para $35,9 \%$, respectivamente. Os demais componentes químicos foram afetados em menor intensidade.

O teor de lignina da parede celular foi a única característica a se correlacionar significativamente com a DIVMS, quando apenas os dados da lâmina foliar total foram considerados (Tabela 5). Nenhum dos componentes químicos da lâmina foliar de topo exibiu correlação significativa com a DIVMS. Nas demais frações do perfilho, correlações altamente significativas entre a DIVMS e as entidades químicas estudadas foram observadas, exceto para o teor protéico da lâmina foliar das folhas inferiores e teor de FDN da bainha foliar. Entretanto, as correlações foram mais altas e generalizadas, quando se consideraram todas as frações do perfilho ou apenas o colmo isoladamente (Tabela 5).

A aparente contradição decorrente do confundimento do nível de inserção com maturidade reportada anteriormente explica, também, os baixos coeficientes de correlação obtidos entre a DIVMS e a maioria dos parâmetros estudados, quando somente os dados da lâmina foliar foram considerados (Tabela 5). A correlação entre a DIVMS e os teores de FDN e FDA, embora freqüentemente significativa (VAN SOEST, 1965; MOIR et al., 1975; WILSON et al., 1983; WILSON e HATTERSLEY, 1989; e MASAOKA et al., 1991), apresentou coeficientes de correlação quase nulos na lâmina foliar. VAN SOEST (1994) ressalta que a associação da fibra com a digestibilidade depende do grau em que ela se associa aos teores de lignina. Se esta associação é baixa, como comumente ocorre nas gramíneas tropicais (BUTTERWORTHe DIAZ, 1970), o conteúdo de fibra da forrageira não será bom indicador da digestibilidade. De fato, a correlação entre os teores de FDN e FDA e os teores de lignina não foram significativos na lâmina foliar, com valores de $\mathrm{r}$ igual a 0,02 e 0,32 ( $>>0,05)$, 
Rev. bras. zootec.

Tabela 4 - Teores de lignina em lâminas e bainhas foliares e em colmos, segundo as espécies e os níveis de inserção

Table 4 - Lignin content in tillers fractions, according to the species and insertion levels

\begin{tabular}{|c|c|c|c|c|}
\hline \multirow{2}{*}{$\begin{array}{l}\text { Fração do } \\
\text { Perfilho } \\
\text { Tillerfraction }\end{array}$} & \multicolumn{2}{|c|}{$\begin{array}{l}\text { Espécie } \\
\text { Specie }\end{array}$} & \multicolumn{2}{|c|}{$\begin{array}{l}\text { Nível de inserção } \\
\text { Insertion level }\end{array}$} \\
\hline & $\begin{array}{c}\text { Capim-elefante } \\
\text { Elephantgrass }\end{array}$ & $\begin{array}{c}\text { Capim-setária } \\
\text { Setariagrass }\end{array}$ & $\begin{array}{l}\text { Topo } \\
\text { Top }\end{array}$ & $\begin{array}{l}\text { Base } \\
\text { Botton }\end{array}$ \\
\hline & \multicolumn{4}{|c|}{ Lignina (\% FDN) (Lignin $[\% N D F])$} \\
\hline $\begin{array}{l}\text { Lâmina foliar } \\
\text { Leaf blade }\end{array}$ & $7,6^{\mathrm{Aa}}$ & $6,7^{\mathrm{Ba}}$ & $6,8^{\mathrm{ABa}}$ & $7,6^{\mathrm{Ba}}$ \\
\hline $\begin{array}{l}\text { Bainha foliar } \\
\text { Leaf sheath }\end{array}$ & $8,9^{\mathrm{Aa}}$ & $7,0^{\mathrm{Bb}}$ & 7,9 $\mathrm{Aa}$ & $8,0^{\mathrm{Ba}}$ \\
\hline $\begin{array}{l}\text { Colmo } \\
\text { Stem }\end{array}$ & $8,2^{\mathrm{Aa}}$ & $8,4^{\mathrm{Aa}}$ & $6,4^{\mathrm{Bb}}$ & $10,1^{\mathrm{Aa}}$ \\
\hline
\end{tabular}

Médias seguidas de letras diferentes, minúsculas nas linhas, comparam espécies ou níveis de inserção e maiúsculas, nas colunas são diferentes $(P<0,05)$ pelo teste Newman Keuls.

Means followed by different letters, small in the row, compare species or insertion levels; capital in the column are different $(P<.05)$ by Newman Keuls test.

Tabela 5 - Correlação entre a digestibilidade in vitro da matéria seca e as entidades químicas em frações do perfilho

Table 5 - Correlation among the in vitro dry matter disappearance and chemical entities of tillers fractions

\begin{tabular}{|c|c|c|c|c|c|}
\hline \multirow[t]{2}{*}{$\begin{array}{l}\text { Fração do perfilho } \\
\text { Tiller fraction }\end{array}$} & \multirow[t]{2}{*}{$\begin{array}{c}\text { Número de } \\
\text { observações } \\
\text { Observation numbers }\end{array}$} & \multicolumn{4}{|c|}{$\begin{array}{c}\text { Componente químico } \\
\text { Chemical component }\end{array}$} \\
\hline & & $\begin{array}{l}\text { FDN } \\
N D F\end{array}$ & $\begin{array}{l}\text { FDA } \\
A D F\end{array}$ & $\begin{array}{l}\mathrm{PB} \\
C P\end{array}$ & $\begin{array}{l}\text { Lignina } \\
\text { Lignin }\end{array}$ \\
\hline $\begin{array}{l}\text { Lâmina foliar total } \\
\text { Total leaf blade }\end{array}$ & 24 & $-0,05$ & $-0,07$ & 0,03 & $-0,53 *$ \\
\hline $\begin{array}{l}\text { Lâmina foliar topo } \\
\text { Top leaf blade }\end{array}$ & 12 & $-0,39$ & $-0,12$ & 0,07 & $-0,30$ \\
\hline $\begin{array}{l}\text { Lâmina foliar base } \\
\text { Botton leafblade }\end{array}$ & 12 & $-0,71 * *$ & $-0,63^{*}$ & 0,12 & $-082 * * *$ \\
\hline $\begin{array}{l}\text { Bainha foliar total } \\
\text { Total sheath blade }\end{array}$ & 24 & -022 & $-063 * * *$ & $0,51 * *$ & $-0,48 * *$ \\
\hline $\begin{array}{l}\text { Colmo total } \\
\text { Total stem }\end{array}$ & 20 & $-082 * * *$ & $-0,87 * * *$ & $0,80 * * *$ & $-0,88 * * *$ \\
\hline $\begin{array}{l}\text { Todas as frações } \\
\text { Total fractions }\end{array}$ & 68 & $-0,56 * *$ & $-0,72 * * *$ & $0,65 * * *$ & $-0,62 * * *$ \\
\hline
\end{tabular}

respectivamente, mas foram significativos, quando todas as frações foram agrupadas com valores de $0,36 \mathrm{e}$ $0,51(\mathrm{P}<0,001)$, o que corrobora aquela observação. $\mathrm{O}$ mesmo pode ser dito quando as frações do perfilho foram tratadas separadamente, em que os coeficientes de correlação entre o teor de FDN e a lignina foram $-0,04(\mathrm{~ns}) ; 0,67(\mathrm{P}<0,01) ; 0,10(\mathrm{~ns}) ; \mathrm{e} 0,70(\mathrm{P}<0,01)$ para as lâminas foliares de topo, de base, bainha foliar e colmo, respectivamente.

\section{Conclusões}

Espécie, fração do perfilho e nível de inserção determinaram intensa variação nos coeficientes de DIVMS e composição química.

O efeito da estação de crescimento sobre a DIVMS e composição química foi pequeno e inconsistente.

Apenas o teor de lignina apresentou correlação significativa com a DIVMS da lâmina foliar. 
Os teores de FDN, FDA, PB e lignina propiciaram correlações altamente significativas com a DIVMS do colmo, quando todas as frações do perfilho foram consideradas.

\section{Referências Bibliográficas}

AKIN, D.E., ROBINSON, E.L., BARTON II, F.E. et al. 1977. Changes with maturity in anatomy, histochemistry, chemistry, and tissue digestibility of bermudagrass plant parts. J. Agric. Food Chem., 25(1):179-186.

ASSOCIATION OF OFICIAL AGRICULTURAL CHEMISTAOAC. 1970. Official methods of analyses. Washintong, D.C.: AOAC. $1015 \mathrm{p}$.

BUTTERWORTH, M.H., DIAZ, J.A. 1970. Use of equations to predict the nutritive value of tropical grasses. J. Range Manag., 23(1):55-58.

GOMIDE, J.A. 1988. Fisiologia das plantas forrageiras e manejo das pastagens. Inf. Agropec., 13(153-154):11-18.

LANGER, R.H.M. 1972. How grasses grow. London: Edward Arnold. 60p. (Studies in Biology's, 34)

MARTEN, G.C., HALGERSON, J.L. A two stage in vitro rumen fermentation technique for estimating the digestible labs. Minneapoles, Departament of Agronomy and Plant Genetics. University of Minnesota, USDA, s.d. 6 p. (Mimeografado).

MASAOKA, Y., WILSON, J.R., HACKER, J.B. 1991. Selecting for nutritive value in Digitaria milanjiana. 3. Relation of chemical composition and morfological and anatomical characteristics to the difference in digestibility of divergently selected full sibs, and comparison with D. eriantha ssp. pentzii (pangola grass). Aust. J. Exper. Agric., 31(5):631-638.

McLEOD, M.N., MINSON, D.J. 1969. Sources of variation in the in vitro digestibility of tropical grass. J. Brit. Grassl. Soc., 24(3):244-249.

MOIR, K.W., LAWS, L., BLIGT, G. 1975. The relative importance of the total cell and quantity of digested cell wall in the regulation of the voluntary intake of grass hays by sheep. $J$. Agric. Sci., 85(1):39-43.

RALPH, J., HELM, R.F. Lignin/hydroxycinnamic acid/ polysaccharide complexes: Synthetic models for regiochemical characterization. In: JUNG, H.G et al. (Eds.) FORAGE CELL WALL STRUCTURE AND DIGESTIBILITY. 1991, Madison. Proceedings... Americam Society of Agronomy, Crop Science Society of America, Soil Science Society of America, 1993. p.201-246.
SILVA, D.J. 1990. Análise de alimentos: métodos químicos e biológicos. 2.ed. Viçosa: Imprensa Universitária UFV. 165p.

TILLEY, J.M., TERRY, R.A. 1963. A two stage technique for the in vitro digestion of forage crops. J. Brit. Grassl. Soc., 18(2):104-111.

VAN SOEST, P.J. 1965. Symposium on factors influencing the voluntary intake of herbage by ruminants: Voluntary intake relation to chemical composition and digestibility. J. Anim. Sci., 24(3):834-844.

VAN SOEST, P.J. 1982. Nutritional ecology of the ruminant. Corvallis: O\&B Books. 374p.

VAN SOEST, P.J. 1994. Nutritional ecology of the ruminant. 2 .ed Ithaca: Cornell University. 476p.

WILSON, J.R. 1976a. Variation of leaf characteristics with level of insertion on a grass tiller. I. Development rate, chemical composition and dry matter digestibility. Aust.J. Agric. Res., 27(3):343-354.

WILSON, J.R. 1976b. Variation of leaf characteristics with level of insertion on a grass tiller. II. Anatomy. Aust. J. Agric. Res., 27(3):355-364.

WILSON, J.R. An interdisciplinary approach for increasing yield and improving quality of forages. In: INTERNACIONAL GRASSLAND CONGRESS, 15, 1985, Kyoto, Procedings... Kyoto: The Science Concil of Japan, The Japanese Society of Grassland Society of America, 1985. p.49-55.

WILSON, J.R., BROWN, R.H., WINDHAM, W.R. 1983. Influence of leaf anatomy on the dry matter digestibility of $\mathrm{C}_{3}, \mathrm{C}_{4}$, and $\mathrm{C}_{3} / \mathrm{C}_{4}$ intermediate types of Panicum species. Crop Sci., 23(1):141-146.

WILSON, J.R., HATTERSLEY, P.W. 1989. Anatomical characteristics and digestibility of leaves of Panicum and other grass genera of $\mathrm{C}_{4}$ photosynthetic pathway. Aust. J. Agric. Res., 40(1):125-136.

Recebido em: 20/10/98

Aceito em: 20/06/99 